\title{
Aisthesis
}

Firenze University Press

www.fupress.com/aisthesis

OPEN ACCESS

Citation: F. Vitale (2021) The Teleological Program. Ernst Mayr's Teleonomy from Philosophy to Cybernetics (or Kant's Revenge). Aisthesis 14(2): 17-28. doi: 10.36253/Aisthesis-12754

Copyright: (c) 2021 F. Vitale. This is an open access, peer-reviewed article published by Firenze University Press (http://www.fupress.com/aisthesis) and distributed under the terms of the Creative Commons Attribution License, which permits unrestricted use, distribution, and reproduction in any medium, provided the original author and source are credited.

Data Availability Statement: All relevant data are within the paper and its Supporting Information files.

Competing Interests: The authors have declared that no competing interests exist.

\section{The Teleological Program. Ernst Mayr's Teleonomy from Philosophy to Cybernetics (or Kant's Revenge)}

\author{
Francesco Vitale \\ Università degli Studi di Salerno (Italy) \\ fvitale@unisa.it
}

\begin{abstract}
Teleology is still a source of embarrassment for the natural sciences and in particular for biology that seems unable to describe and explain the genesis and structure of life without it. How is it possible for something not yet existing to determine the occurrence of what is temporally prior to it? How can the future cause the present and the past? In what follows we intend to examine the elaboration of the biological notion of «teleonomy» through the writings of Ernst Mayr, in order to verify its rigor and strenght with respect to the criteria of scientificity adopted by Mayr himself, in particular with respect to the adoption of the cybernetic model. On the one hand, to show the consistency of the debt that the so-called scientific discourse owes to the philosophical tradition, where it elaborates notions that claim to be emancipated. On the other hand, to detect, within the scientific discourse itself, the limits that a certain position that claims to be scientifically founded can impose on research, becoming a dogmatic assumption.
\end{abstract}

Keywords: Teleology, Teleonomy, Cybernetics, Biology, Philosophy.

Teleology is still a source of embarrassment for the natural sciences and in particular for biology that seems unable to describe and explain the genesis and structure of life without it. In fact, teleology is one of the oldest devices developed by the philosophical tradition, at the origin of several conceptions of nature and life now considered purely metaphysical and without foundation from a scientific point of view, especially because the teleological explanation seems to imply a reversal of efficient causality, the only one considered valid in the mechanistic horizon of modern science. In fact, teleology seems to violate the order of temporal succession of events from the present to the future: how is it possible that something not yet existing determines the occurrence of what is temporally anterior to it? How can the future cause the present and the past?

In short, according to many authoritative philosophers of science, the use of teleology could compromise the scientific status 
of biological sciences, unable to free themselves from metaphysical assumptions inherited from the philosophical tradition. For this reason, teleology is still today at the center of the scientific debate, as evidenced by the numerous publications dedicated to the problem. One of the most accredited solutions in nowadays' biology is represented by the notion of "teleonomy», introduced by Colin S. Pittendrigh (Pittendrigh [1958]) and later finely elaborated by Ernst Mayr, evolutionary biologist of Darwinist matrix, authoritative representative of the so-called "modern synthesis" or "evolutionary synthesis" (cf. Jepsen, Simpson, Mayr [1949]). Beginning with Cause and Effect in Biology, first published in 1961 and later collected in Toward a New Philosophy of Biology (Mayr [1988a]), to The Idea of Teleology (Mayr [1992]), Mayr devoted a series of writings to defining the concept of «teleonomy» in order to demonstrate the necessity and legitimacy of teleological explanations within the biological sciences. The most articulate is undoubtedly The Multiple Meanings of teleology, published in Toward a New Philosophy of Biology (Mayr [1988b]), a revised and augmented version of Teleological and Teleonomic. A New Analysis (Mayr [1974]) ${ }^{1}$. According to Mayr, in order to free teleology from its compromising philosophical origin and transform it into a scientific concept, it is necessary to adopt the perspective of cybernetics and in particular the notion of "program». As is well known, in 1948 Norbert Wiener had pioneered the extension of the cybernetic model to life-sciences (and beyond) with the publication of Cybernetics, or Control and Communication in the Animal and the Machine (Wiener [1965]). Mayr would be among the first to take this path, which would soon allow François Jacob, Jacques Monod and André Lwoff to explain the mechanism that regulates the genetic control of protein synthesis by DNA, a discovery which

\footnotetext{
1 To complete the corpus of Mayr's writings devoted to teleology, one must also take into account the following The Evolution of Living Systems (Mayr [1964]) and The Concept of Finality in Darwin and After Darwin (Mayr [1988c]) first published in 1983.
}

would award them with the Nobel Prize for Medicine in 1965 and constituting a decisive step for the very status of modern life sciences (cf. Debru, Morange, Worms [2012]). However, in his personal path of research, Mayr does not renounce the close confrontation with the philosophical tradition: on the one hand, to demonstrate that the notion of teleonomy is immune to the objections to which "philosophical» teleology is subject, on the other, paradoxically, to demonstrate that this notion is consistent with the oldest source of teleological thought, namely with the lesson of Aristotle, which may be recovered in the scientific context, once freed from the interpretations that, since the Middle Ages, made it the matrix of positions untenable from a scientific point of view, that is, both that of "vitalism» and that which Mayr appropriately calls "cosmic teleology», that is, of the idea of a general finality of nature with its theological and humanist variants (the finalistic order of nature as a demonstration of the existence of God, man as the apex of the evolution of life oriented towards perfection, etc.) (Mayr [1988b]: 40, 56).

In what follows, we intend to examine the elaboration of the notion of «teleonomy» through Mayr's writings, in order to verify its rigor with respect to the criteria of scientificity he himself adopted, in particular with respect to the adoption of the cybernetic model. On the one hand, to show the consistency of the debt that the socalled scientific discourse contracts, more or less consciously, towards the philosophical tradition from which it claims to be emancipated. On the other hand, and more deeply, to detect the limits that a certain scientific hypothesis can impose on research once it is considered a definitive acquisition, an incontrovertible truth. In this horizon, we will be guided by The Idea of teleology (Mayr [1992]), the essay in which Mayr retraces his own path in the elaboration of the notion of «teleonomy» in order to show its validity and effectiveness in the horizon of the (then) most recent biological research; this will allow us to reconstruct its evolution with reference to the previous texts to which Mayr himself refers. 


\section{STARTING WITH KANT, VERSUS KANT}

The starting point of Mayr's research seems to take us back to Kant's position of the problem in the opening of the second part of the Critique of Judgement, the Critique of Teleological Judgement (Kant [1790]: $\$ 65$ ): the philosophy of science of the twentieth century would still be conditioned by the mechanism of Cartesian matrix, at the origin of its reductionist orientation and then by the rejection of teleology from the sciences (which actually goes back at least to Roger Bacon). Precisely for this reason, the philosophy of science would not yet be able to describe and explain the phenomena of living nature:

Refutation of a finalistic interpretation of evolution or of nature as a whole, however, did not eliminate teleology as a problem of philosophy. For the Cartesians any invoking of teleological processes was utterly unthinkable. Coming from mathematics and physics, they had nothing in their conceptual repertory that would permit them to distinguish between seemingly end-directed processes in inorganic nature, and seemingly goal-directed processes in living nature. They feared, as shown particularly clearly by Nagel, that making such a distinction would open the door to metaphysical, nonempirical considerations. All their arguments, based on the study of inanimate objects, ignored the common view, derived from Aristotle and strongly confirmed by Kant, that truly goal-directed and seemingly purposive processes occur only in living nature. Yet the (physicalist) philosophers ignored the study of living nature and the findings of the biologists. Instead they used teleology in order to exercise their logical prowess. (Mayr [1992]: 120, my italics)

In The multiple Meanings of Teleology, the reference to Kant is in this sense explicit and yet limited to the location of the problem ${ }^{2}$, in fact, Mayr believes that Kant's investigation of the phenomena of living nature is irreparably compromised by the still «primitive» state of the knowledge then

2 «Even Kant (1790) believed that numerous phenomena of nature could not be explained purely mechanistically. He therefore postulated final causes» (Mayr [1988c]: 235). accessible and elaborated in the horizon of philosophical «vitalism»:

Kant was a strict mechanist with respect to inanimate nature, but he saw teleological forces acting in all processes of the living world. [...] Yet his familiarity with the work of Buffon, Haller, Wolff, and Blumenbach could get him only as far as these authors had gone, with the exception of the solution of some problems of physiology and a rather primitive systematic and anatomy, it must be realized that biology at the time when Kant wrote his Critique of Judgement (1790) and his Opus Postumum was virtually a terra incognita. The birth of scientific biology falls in the period from 1828 to 1865, characterized by the names von Baer, Schwann, Schleiden, Liebig, Bernard, Virchow, Darwin and Mendel. (Mayr [1988b]: 57).

The argument would seem legitimate and, in any case, sufficient to justify the untenability of Kantian teleology in the context of modern natural sciences, were it not that the Critique of Teleological Judgement does not simply resolve itself into a description of the phenomena of the living world, based on the proto-biological knowledge of its time. On the contrary, Kantian reflection is primarily concerned with defining the epistemological status of the teleological evaluation of the phenomena of life forms and of nature in general. A reflection that concludes with the affirmation of the impossibility to consider teleology as "constitutive» of the phenomena of nature. In virtue of the analogy with the human practical-technical behavior that constitutes its exclusive foundation, teleology can only be used as a heuristic - «regulative» - principle for the investigation of the phenomena of the living world.

Thus, we are bringing forward a teleological ground where we endow a concept of an object - as if that concept were to be found in nature instead of in ourselves - with causality in respect of the object, or rather where we represent to ourselves the possibility of the object on the analogy of a causality of this kind - a causality such as we experience in ourselves - and so regard nature as gifted of a capacity of its own for acting technically; whereas if we did not ascribe such a mode of operation to nature, its causality would 
have to be regarded as blind mechanism. But this is a different thing from crediting nature with causes acting designedly, to which it may be regarded as subjected in following its laws. The latter would mean that teleology is based-not merely on a regulative principle, directed to the simple judging of phenomena, but rather on a constitutive principle available for deriving natural products from their causes: with the result that the concept of a natural end would no longer belong to reflective, but to determining-judgement. (Kant [1790]: \$ 61)

Kant therefore excludes the possibility of attributing to finality an objective, ontological value, contesting, in fact, the position of Aristotle and the metaphysical tradition derived thereof. Our hypothesis is that this is precisely the reason why Mayr refuses the comparison with Kant, as seems to be confirmed by a passage of Teleological and Teleonomic. A New Analysis, apparently more generous towards Kant but amended in The Multiple Meanings of teleology:

He [Kant] clearly saw two points, first that no explanation of nature is complete that cannot account for the seeming purposiveness of much of the development and behavior of living organisms, and secondly that the purely mechanical explanations available at his time were quite insufficient to explain teleological phenomena. Unfortunately, he subscribed to the prevailing dogma of his period that the only legitimate explanations were purely mechanical («Newtonian») ones, which left him without any explanation for all teleological phenomena. He therefore concluded that the true explanation was out of our reach and that the most practical approach to the study of organisms was to deal with them "as if they were designed». Even though he was unable to free himself from the design-designed analogy, he stressed the heuristic value of such an approach: It permits us to make products and processes of nature far more intelligible than trying to express them purely in terms of mechanical laws. (Mayr [1974]: 108, my italics)

According to our hypothesis, the limit of Kantian teleology, for Mayr, would not consist so much or exclusively in the scientific unreliability of its «proto-biological» sources, but first of all in the exclusively heuristic value - «regulative», certainly not "practical» - attributed to teleological evaluation and above all in the recourse to analogy with intentional (practical-technical) human behavior as its irreducible condition of possibility. In fact, as much as Mayr also seems to attribute a heuristic value to the teleological evaluation of the phenomena of the living world (Mayr [1988b]: 53-55), in The idea of Teleology he refers to a «genuine goal-directed processes» (Mayr [1992]: 125) as phenomena specifically teleonomic, on the basis of the distinction we have already encountered between «truly goal-directed and seemingly purposive processes» that refers in extreme synthesis to the section of «The Multiple Meanings of Teleology» entitled «Seemingly or genuinely goaldirected processes» (Mayr [1988b]: 44-50). In this section, Mayr delimits the boundaries of the scope of natural phenomena that can be described and explained through the notion of "teleonomy», affirming its «constitutive» validity, that is, the possibility of attributing to it an objective, ontological value, thus allowing us to understand the most stringent reason for the lack of comparison with Kant. In fact, Kantian teleology not only prevents the "constitutive» determination of finality as a genetic-structural condition of the phenomena of the living world, but also exposes teleology to one of the objections that have been raised against it within the scientific debate, and perhaps the most stringent: the so-called «anthropomorphism» that accuses precisely the analogical derivation of teleology. It is Mayr himself who defines it in these terms, dedicating to it ample space and a central position in the list of objections raised to the scientific use of teleology and of which Mayr gives an account to demonstrate the inefficacy with respect to the notion of «teleonomy» that he is preparing to define:

Teleological language introduces anthropomorphism into biology. Many philosophers, indeed, have made human intentions and purposive acts the starting point of their analysis of goal-directed activities in other organisms. This introduces concepts such as purpose, intention, and consciousness into the discus- 
sion and ties the whole problem to human psychology; but it seems to me that this is a poor foundation for an analysis of goal-directed activities in the non-human living world. In my own treatment I have therefore refrained from using anthropomorphic language, particularly the terms "purpose» and «intention", when explaining teleonomic phenomena in animals and plants. The term goal-directed is strictly descriptive, while terms like purpose or intention introduce psychological problems that are irrelevant to our immediate objective. (Mayr [1992]: 122)

At this point, we should verify the true consistency of the distinction, which Mayr assumes to be rigorous, between «truly goal-directed and seemingly purposive processes», and in particular we should verify whether, through the decisive introduction of the cybernetic armamentarium, Mayr succeeds in his intent to subtract the teleonomy to the analogy with the human intentional behavior, which is expressed, according to the Kantian model, in the technical production of artifacts and consequently, if Mayr succeeds in affirming the objective determination of the teleonomic processes.

\section{THE SPECTRE OF KANT}

In The Idea of Teleology the section Teleonomic Processes opens with an important clarification, concerning the use of the notion of teleonomy following its introduction by Pittendrigh:

The term teleonomic has been used with various meanings. When Pittendrigh introduced the term, he failed to provide it with a rigorous definition. As a result, various authors used it either for programmed functions or for adaptedness as did for instance B. Davis, G. G. Simpson, Monod, and Curio. I restricted the term teleonomic to programmed activities and now provide the following definition: a teleonomic process or behavior is one that owes its goal-directedness to the operation of a program. (Mayr [1992]: 126) 3

\footnotetext{
${ }^{3}$ Mayr develops his critique of Monod's use of the notion of teleonomy in Mayr (1988b): 48. Based on the Darwinian principle of natural selection, evolutionary adaptation
}

This definition, which Mayr claims to be «narrow», is, however, sufficiently broad to apply to «processes» and «behaviors» of a very different order, namely, as he points out immediately afterwards, both the physical-chemical processes that determine the ontogeny of living beings at the molecular level and the behavior of animals in their habitat, the object of study of ethology:

The term teleonomic thus implies goal-direction of a process or activity. It deals strictly with proximate causations. They occur in cellular-developmental processes and are most conspicuous in the behavior of organism. «Goal-directed behavior ... is extremely widespread in the organic world; for instance, most activities connected with migration, food-getting, courtship, ontogeny and all phases of reproduction are characterized by such goal orientation. The occurrence of goal-directed processes is perhaps the most characteristic feature of the world of living organism». (Mayr [1992]: 126)

The passage quoted in quotation marks, as well as the unquoted definition preceding it, comes from Teleological and Teleonomic (Mayr [1974]: $98)^{4}$, with a small but significant difference signaled by the hanging points, In the most recent version Mayr has in fact removed a parenthesis: "goal-directed behavior (in the widest sense of this word)» (Mayr [1974]: 98). This is actually a parenthesis that could prove compromising in that it allows one to recognize the source of this expanded conception of goal-directed behavior: it is the article of Rosenblueth, Wiener and Bigelow, Behavior, Purpose and Teleology, published in 1943, with which Mayr, in 1974, admitted to having incurred a fundamental debt:

cannot be explained in terms of a teleonomic process, i.e., as the result of a process pre-determined by the genetic «program» of an individual or species. Indeed, this would result in the illegitimate attribution of a general purpose to the evolution of living beings. In Vitale (2017) I noted this limitation in Monod in the context of a deconstruction of the biological application of the cybernetic model, the more general results of which I believe, however, can also apply to Mayr.

${ }^{4}$ The same lines can be found in Mayr (1988b): 45 . 
We owe a great debt of gratitude to Rosenblueth et al. (1943) for their endeavor to find a new solution for the explanation of teleological phenomena in organisms. They correctly identified two aspects of such phenomena, (1) that they are seemingly purposeful being directed toward a goal, and (2) that they consist of active behavior. (Mayr [1974]: 100)5

This is one of the milestones of cybernetics in which the authors use the notion of «negative feed-back» to describe in information-science terms the goal-directed behavior of animals by analogy with machines equipped with servomechanisms. However, there is no trace of the notion of «program» or even the extension of the cybernetic model to onto-genetic processes; especially the extended definition of "goal-directed behavior» implies the explicitly analogical reference to human voluntary action:

Active behavior may be subdivided into two classes: purposeless (or random) and purposeful. The term purposeful is meant to denote that the act or behavior may be interpreted as directed to the attainment of a goal ... Purposeless behavior then is that which is not interpreted as directed to a goal. The vagueness of the words «may be interpreted» as used above might be considered so great that the distinction would be useless. Yet the recognition that behavior may sometimes be purposeful is unavoidable and useful, as follows. The basis of the concept of purpose is the awareness of «voluntary activity». Now, the purpose of voluntary acts is not a matter of arbitrary interpretation but a physiological fact. When we perform a voluntary action what we select voluntarily is a specific purpose, not a specific movement. (Bigelow, Rosenblueth, Wiener [1943]: 18)

Thus, the extension of the notion of goaldirected behavior to onto-genetic processes is made by Mayr, and as such appears problematic, at least with respect to the analogical assumption that justifies its application: the recognition of voluntary intentional activity. Interpreting onto-genetic processes as a form of «behavior»,

\footnotetext{
${ }^{5}$ This line also appears in The Multiple Meanings of Teleology (see Mayr [1988b]: 46).
}

even if in this extended sense, one takes the risk of attributing some kind of intentionality to them, exposing teleology once again to the accusation of anthropomorphism (which does not seem to worry cybernetics in the least, interested in the elaboration of a model for the comparative study of goal-directed behavior in machines and organisms, without any ontological claim). In The Idea of Teleology, Mayr seems to solve the problem precisely through the notion of "program»: both the onto-genetic development of an organism as well as the behaviors of organisms, the result of this development, would manifest a «genuine» teleonomic orientation, as they would be predetermined by a program that prescribes the goal to be achieved and dictates the instructions necessary to achieve it.

In The Idea of Teleology Mayr again refers to Teleological and Teleonomic to impose a further restriction on teleonomic phenomena, retracting what he had previously argued precisely on the basis of the article by Roseblueth, Bigelow and Wiener, even though he had just confirmed the extended notion of "goal-directed behavior» he had drawn from it and still necessary to the definition of «teleonomy»:

In my original proposal I suggested that one might expand the application of the term teleonomic to include also the functioning of human artifacts (e.g., loaded dice) that are fixed in such a way as to assure a wanted goal. This extended use of the term has been criticized, and I now consider that human artifacts are only analogs. Truly teleonomic activities depend on the possession of a program. (Mayr [1992]: 127)

At this point the argumentation appears really convoluted if not paradoxical: Mayr intends to exclude human artifacts from the field of application of teleonomics, the definition of which, however, necessarily implies the analogy with at least one human artifact, namely the "program» of electronic computers. In Teleological and Teleonomic, Mayr had defined the notion of "program» precisely in this analogical perspective and with reference to the work of Roseblueth, Bigelow and Wiener: 
The key word in my definition of "teleonomic» is the term "program». [...] The term is taken from the language of information theory. A computer may act purposefully when given appropriate programmed instructions. Tentatively program might be defined as coded or prearranged information that controls a process (or behavior) leading it toward a given end. ... My definition of program is deliberately chosen in such $a$ way as to avoid drawing a line between seemingly "purposive» behavior in organisms and manmade machines. The simplest program is perhaps the weight inserted into loaded dice or attached to a "fixed» number wheel so that they are likely to come to rest on a given number. A clock is constructed and programmed in such a way as to strike at the full hour. Any machine which is programmed to carry out goal-directed activities is capable of doing it «mechanically». (Mayr [1974]: 102) ${ }^{6}$

In The Idea of Teleonomy the rejection of the analogy with human-produced artifacts produces a contradictory if not downright paradoxical effect: Mayr, on the one hand, claims, as we have seen, that human artifacts are teleonomic only by analogy with ontogenetic processes and animal behavior, because only the latter would be endowed with a "program». On the other hand, he must necessarily resort to the analogy with man-made computers to describe the essential characteristics of the "program» with which living organisms would be endowed, of which it would constitute the onto-genetic cause:

The existence of programs, of course, is in no way in conflict with natural laws. All the physico-chemical processes that take place during the translation and execution of a program strictly obey natural laws. But to neglect the role of information and instruction inevitably results in a most misleading description of a program. Could one explain a computer strictly in terms of natural laws, carefully avoiding any reference to information and instruction? (Mayr [1992]: 126). ${ }^{\text {? }}$

${ }^{6}$ The same passage is found in The Multiple Meanings of Teleology (see Mayr [1988b]: 49).

7 This text is absent in both Mayr (1974) and Mayr (1988b).
The paradoxical reversal of the analogy with human practical-technical behavior, which for Kant (as for Rosenblueth, Bigelow and Wiener) constituted the necessary condition for the exclusively «regulative» use of teleology for the evaluation of organic phenomena, seems to reproduce the Freudian logic of the «kettie», leading us to draw the relative consequences: If for Freud the affirmation of contradictory theses in the same argument ("the cauldron was already pierced when you lent it to me», "the cauldron was not pierced when I gave it back to you») is the symptom of an unsuccessful removal, then at this point it is more than legitimate to suppose that this unfortunate paradox is due to the need to avoid the return of Kant's specter, which must be removed in order to sustain a «constitutive» use of teleonomy. Therefore, it seems equally clear that in order to give teleonomy an ontological status, constitutive with respect to onto-genetic processes and animal behavior, Mayr must demonstrate that the latter are in themselves endowed with a true cybernetic program, that such a program does in fact exist, and that it does in fact function as a cybernetic program.

\section{THE ONTOLOGICAL PROGRAM AND KANT'S REVENGE}

As we have seen, in order to define the «rigorous» sense of teleonomy, such as to legitimize the «scientific» use of this notion, Mayr would have to demonstrate the existence of a goal-directed «program» within organisms capable of determining first of all their onto-genesis. In particular, one must demonstrate the existence of the goal of the "program» and the instructions necessary for its realization within the «program» itself, «the goal is already coded in the program which directs these activities» (Mayr [1992]: 134). This last point is essential because it would allow us to define the "program» as the initial and exclusive cause of onto-genesis, thus solving the problem of the inversion of the causal process that had made teleology unusable in a «rigorous» scientific con- 
text; in fact, understood in this way, the program would play the role of «efficient cause» and «final cause» at the same time, being the cause that starts the teleonomic process, which can therefore be explained in terms of a linear physical-chemical process:

All teleonomic behavior is characterized by two components. It is guided by "a program» and it depends on the existence of some end point, goal, or terminus which is foreseen in the program which regulates the behavior. This end point might be a structure (in development), a physiological function, the attainment of a geographical position (in migration), or a "consummatory act" in behavior. Each program is the result of natural selection, constantly adjusted by the selective value of the achieved end point. The key word in the definition of teleonomic is program. The importance of the recognition of the existence of programs lies in the fact that a program is (1) something material and (2) something existing prior to the initiation of the teleonomic process. This shows that there is no conflict between teleonomy and causality. (Mayr [1992]: 127)

This passage is the result of the conjunction (indicated by the asterisk) of two passages present in Teleological and Teleonomic but in different places and with a significant modification ${ }^{8}$. The second part of the quotation involves the elision of a passage that allows us to note that at the time of Teleological and Teleonomic and then The Multiple Meaning of Teleology, Mayr was much more cautious in asserting the existence of a goal-directed program responsible for the ontogeny of organisms, preferring a still analogical and, above all, hypothetical, use of this notion because of the still scarce biological knowledge regarding the nature and functioning of such a program:

The key word in my definition of «teleonomic» is the term «program». Someone might claim that the difficulties of an acceptable definition for teleological language in biology had simply been transferred to the term "program<. This is not a legitimate objection,

\footnotetext{
${ }^{8}$ See Mayr (1974): 99, 102. The same passages are present in Mayr (1988b): 45, 48.
}

because it neglects to recognize that, regardless of its definition, a program is (1) something material, and (2) exists prior to the initiation of the teleonomic process. Hence, it is consistent with a causal explanation. Nevertheless, it must be admitted that the concept "program" is so new that the diversity of meanings of this term has not yet been fully explored. The term is taken from the language of information theory. A computer may act purposefully when given appropriate programmed instructions. Tentatively program might be defined as coded or prearranged information that controls a process (or behavior) leading it toward a given end. (Mayr [1974]: 102)

The latter definition is taken up in The Idea of Teleology, but blurring, as far as possible, both the explicit analogical reference to computer programs and the hypothetical value of the analogy: "A program might be defined as coded or prearranged information that controls a process (or behavior) leading it toward a goal» (Mayr [1992]: 127). In fact, in The Idea of Teleology, the demonstration of the existence of programs that preside over the ontogeny and behavior of organisms is taken for granted and attributed to genetic biology, which in turn uses models developed by cybernetics:

The program contains not only the blueprint of the goal but also the instructions of how to use the information of the blueprint. A program is not a description of a given situation but a set of instructions. Accepting the concept of program seems to cause no difficulties to a biologist familiar with genetics or any scientist familiar with the working of computer. (Mayr [1992]: 128)

Therefore, the demonstration is entrusted to genetic biology and to the discoveries concerning the role that DNA plays in regulating the protein syntheses that preside over the construction of the organism. Mayr in fact refers to La Logique du vivant (1970) by François Jacob and to a short article by Max Delbrück, Aristotle-totle-totle (1971) for the «rigorous» scientific definition of the concept of "genetic program» and for

\footnotetext{
${ }^{9}$ The same passage is present in Mayr (1988b): 48.
} 
the demonstration of its existence at the molecular level. Not only that: according to Mayr, the biological definition of the «genetic program» would have been anticipated on an intuitive, not yet scientific, level by the proto-biological thought of the eighteenth and nineteenth centuries and even by the oldest source of teleological thought, namely Aristotle (of course, there is no trace of Kant):

The existence of the program is inferred from its manifestations in the behavior or the activities of the bearer of the program. Concepts, corresponding to program, go back all the way to antiquity. After all, Aristotle's eidos had many of the properties we now ascribe to the genetic program, as was pointed out by Jacob and Delbrück. So did Buffon's moule intérieur as well as the many speculations about inborn memories from Leibniz and Maupertuis to Darwin, Hering, and Semon. As sound as the intuition of these thinkers had been, it required an understanding of the DNA nature of the genotype, before the genetic program could be considered a valid scientific concept. (Mayr [1992]: 128)

In fact, in Delbrück's article there is no scientific demonstration of the existence of a "genetic program» in organisms, nor even a precise definition of this notion; Delbrück, addressing an audience of biologists, evidently believes both already established. The only purpose of the article is to show that Aristotle would have anticipated the idea of "genetic program» in De generatione animalium. Without going into the merits of a controversial and widely debated issue among Aristotelian scholars ${ }^{10}$, nor of the scarce scientific (i.e. philological and hermeneutical) «rigor» of Delbrück's alleged demonstration, which Mayr nonetheless claims [holding solid?], we limit ourselves to noting the result, insofar as it allows us to understand the salient characteristics that the biologist attributes to the "genetic program», believing that he has found them in Aristotelian teleology:

\footnotetext{
${ }^{10}$ For a comprehensive critical overview of interpretations of Aristotelian teleology, see Quarantotto (2005): 13-28. In particular, Quarantotto accurately identifies the limit of interpreting the Aristotelian telos in terms of a "program»: the "reduction of the final cause to a motor cause» (Quarantotto [2005]: 23).
}

It is my contention that Aristotle's principle of the «unmoved mover» originated with his biological studies, and that it was grafted, from here, first onto physics, then onto astronomy, and finally onto his cosmological theology. [...] And yet, "unmoved mover» perfectly describes DNA: it acts, creates form and development, and is not changed in the process. (Delbrück [1971]: 55)

This conception of DNA as exclusively responsible for the ontogeny of the living being, immune to any direct external interference, was in fact sustained first of all by Jacob in La logique du vivant, a text that played an important role in determining the modern paradigm of genetic biology, and that seems to constitute the direct source on which Mayr draws, at least for the obvious terminological and conceptual correspondences:

Heredity is described today in terms of information, messages and code. The reproduction of an organism has become that of its constituent molecules. This is not because each chemical species has the ability to produce copies of itself, but because the structure of macromolecules is determined down to the last detail by sequences of four chemical radicals contained in the genetic heritage. What are transmitted from generation to generation are the «instructions» specifying the molecular structures: the architectural plans of the future organism. They are also the means of executing these plans and of coordinating the activities of the system. In the chromosomes received from its parents, each egg therefore contains its entire future: the stages of its development, the shape and the properties of the living being which will emerge. The organism thus becomes the realization of a program prescribed by its heredity. (Jacob [1973]: 1)

However, Jacob makes no claim to demonstrate the identity of DNA with a cybernetic program. The recourse to cybernetics is exclusively analogical, the reference to computer programs has a heuristic, "regulative» function, Kant would have said ${ }^{11}$. Jacob is very clear on this point; in particular, since it is an analogy, he points out

${ }^{11}$ On the use of the cybernetic model by Jacob I allow myself to refer to Vitale (2018): 103-126. 
the need to take into account the differences that make it possible to construct an equivalence (an equality of relationships) but not an identity between genetic heritage and computer programs:

The aim of modern biology is to interpret the properties of the organism by the structure of its constituent molecules. In this sense, modern biology belongs to the new age of mechanism. The program is a model borrowed from electronic computers. It equates the genetic material of an egg with the magnetic tape of a computer. It evokes a series of operations to be carried out, the rigidity of their sequence and their underlying purpose. In fact, these two kinds of program differ in many ways. First in their properties: one can change at will, the other cannot. In a computer program, information is added or deleted according to the results obtained; the nucleic acid structure, on the contrary, is inaccessible to acquired experience and remains unchanged throughout generations. (Jacob [1973]: 9, my italics)

Paradoxically, Mayr turns the argument of analogical equivalence between DNA and computer programs, evidently taken up by Jacob, against the objection of "anthropomorphism» that should necessarily follow from the analogy between living organisms and machines built by man and endowed by him with a purpose:

The existence and role of somatic programs has been understood by embryologists at least since Kleinenberg (1886). To borrow the term program from informatics is not a case of anthropomorphism. There is a strict equivalence of the "program» of the information theorists, and the genetic and somatic programs of the biologist. (Mayr [1992]: 129)

Mayr's firm refusal to recognize the biological use of the cybernetic model as having an exclusively analogical value and thus a merely «regulative» function, induces him into a further conceptual twist, in open contradiction with what Jacob claimed regarding the "first» and most important difference between cybernetic program and DNA: the program of a computer is necessarily open to intentional external interventions that modify its structure and therefore its functions, while DNA modifications, according to Jacob, depend exclusively on transcription errors in the course of hereditary transmission and on natural selection that intervenes on already formed organisms and populations that eventually inherited such a mutation. In order to hold this principle firm, while at the same time rejecting the analogical difference between DNA and computer programs, Mayr resorts to a notion that in fact has no counterpart in cybernetics:

The study of teleonomic programs has shown that several kinds can be distinguished. A program in which complete instructions are laid down in the DNA of the genotype is called a closed program. Most programs which control the instinctive behavior of insects and lower invertebrates seem to be closed programs. There is, however, another type of program, open programs, which are constituted in such a way that additional information can be incorporated during lifetime, acquired through learning, conditioning, or other experiences. Most behavior in higher animals is controlled by such open programs. Their existence has long been known to ethologists without their introducing a special terminology. (Mayr [1992]: 129)

For this distinction between «open programs» and «closed programs» Mayr in the note refers to himself, to one of his essays, The Evolution of Living Systems (Mayr [1964]), where, however, the distinction is taken from systems theory, which in fact provides a distinction between "open systems» and "closed systems», not from the information sciences, where in fact it does not make sense, or could at most have an empirical and contingent meaning.

Moreover, Mayr himself, starting in 1974, will consider misleading the reference to the notion of «system» for his definition of «teleonomy» precisely because the theory of systems does not deal with the ontogeny of systems but only with the structural dynamics of their functioning ${ }^{12}$.

For Mayr, as for Jacob and Delbrück, the essential point, as we have seen, is the causal func-

12 "The combination of "teleonomic" with the term system is, thus, rather incongruent» (Mayr [1974]: 127). 
tion of the genetic program as the principle of the ontogeny of organisms and the closure of the program with respect to direct external interference, that is, with respect to the possibility that the program may undergo modification due to interaction with the environment. Both principles, as we have seen, cannot be demonstrated and not even inferred from the results of ontogeny of living beings, given the great phenotypic variety with respect to genotypic stability. Rather, they depend on the Darwinian principle of natural selection, posed as an acquired and incontrovertible truth to which the definition and function of the "genetic program» can be traced and commensurate, by analogy with computer programs. In fact, these are the principles of what today is defined by the same biologists, the "central dogma of molecular biology» ${ }^{13}$. Recent research on the ontogeny of organisms and hereditary transmission has in fact shown that these principles, although they have contributed to the achievement of important discoveries, cannot be considered absolutely valid, and above all that their hypostatization as principles has constituted an obstacle for research with respect to significant problems such as the role of environmental interaction in the genetic transmission of several pathologies among which many cancers. In particular, research on methylation has shown that the activation and development of the ontogenesis process of an organism does not depend exclusively on the "genetic program» but on essentially differential chemical signals that can come both from the cytoplasm of the cell, i.e. from outside the nucleus where the DNA is located, and from other cells of the embryo at its earliest stage, activating or silencing the expression of a gene in the chromosome sequence. It has also been shown that the differential value of signals (active/silenced) can be influenced by contingent factors that occur during ontogenetic development and that can also be traced to environmental factors. This new and different approach has led genetic biology to open a new horizon of research,

\footnotetext{
13 Jablonka, Lamm (2005): 31, 152-153. See also Kay (2000) and Keller (2000).
}

called epigenetics, which deals with genetic mutations due to contingent environmental factors, to the pathologies that depend on them and their hereditary transmission, to the intersection between nature and culture (presence of particular chemical substances in the environment, scarcity of food sources or parental care and therefore pollution, famine, war, pandemics or other catastrophes) ${ }^{14}$. This research are rightly defined as «revolutionary» with respect to the Darwinian paradigm of natural selection as the only one responsible for genetic variation and therefore with respect to the entire conceptual framework of the theory of evolution. This research, on an epistemological level, show how misleading it can be, in the horizon of scientific research that wants to be rigorous, the dogmatic hypostatization of a widely shared research hypothesis (as philosophers of science such as Godfrey-Smith are now willing to admit). The latter, reconstructing the scientific debate concerning the import of computer language into biology, first notes that «the "program" concept seems to be applied in biology in an especially broad and unconstrained way, often guided only by very vague analogies with computers and their workings» (Godfrey-Smith [2007]: 111), and then concludes by admitting only a cautious «regulative» use, useful in certain research contexts:

The use of the informational framework is guided by some real features of genetic mechanisms, but also by application of schematic causal model that guides many or most uses of a semantic language. It reflects and reinforces a general disciplinary focus on sequence properties as opposed to others. This would steer us away from the idea that there is some definite but hidden set of properties being posited by such language, which might or might not be real. (GodfreySmith [2007]: 118)

We have thus seen in which conceptual and hermeneutical twists and paradoxes the demon-

${ }^{14}$ Cf. Francis (2011), as well as Jablonka, Lemm (2005). For an interpretation of the deconstructive effects of such research I refer to Vitale (2018): 53-101. 
stration of the scientific objectivity of «teleonomy» as a principle of the ontogeny of organisms remains entangled. Paradoxes and twists that Mayr could perhaps have avoided if he had limited himself to supporting a merely «regulative» use of this notion.

\section{REFERENCES}

Bigelow, J., Rosenblueth, A., Wiener, N., 1943: Behavior, Purpose, Teleology, "Philosophy of Science" 10 (1), pp. 18-24.

Debru, C., Morange, M., Worms, F., 2012: Une nouvelle connaissance du vivant: François Jacob, André Lwoff, Jacques Monod, Rue D’Ulm, Paris. Delbrück, M., 1971: Aristotle-Totle-Totle, in Monod, J., Borek, E. (eds.), Microbes and Life, Columbia University Press, New York, pp. 50-55.

Francis, R. C., 2011: Epigenetics. The Ultimate Mistery of Inheritance, W. W. Norton \& Company, New York.

Godfrey-Smith, P., 2007: Information in Biology, in Hull, D.L., Ruse, M. (eds.), The Cambridge Companion to The Philosophy of Biology, Cambridge University Press, Cambridge, pp. 103119.

Jablonka, E., Lemm, M.J., 2005: Evolution in Four Dimension. Genetic, Epigenetic, Behavioral and Symbolic Variation in the History of Life, MIT Press, Cambridge, MA/London.

Jacob, F., 1973: La logique du vivant. Une histoire de l'hérédité, Paris, Gallimard, 1970; transl. by B.E. Spillman, The Logic of Life. An History of Heredity, Pantheon Books, New York.

Jepsen, G.L., Simpson, G., Mayr, E. (eds.), 1949: Genetics, Paleontology, and Evolution, Princeton University Press, Princeton.

Kant, I., 1790: Kritik der Urteilskraft; transl. by J. C. Meredith, rev. and ed. by N. Walker, Critique of Judgement, Oxford University Press, Oxford, 2007.

Kay, L.E., 2000: Who Wrote the Book of Life. A History of the Genetic Code, Stanford University Press, Stanford.
Keller, E.F., 2000: The Century of Gene, Harvard University Press, Cambridge, MA/London.

Mayr, E., 1964: The Evolution of Living Systems, "Proceedings of the National Academy of Sciences of the United States of America" 51 (5), pp. 934-941.

Mayr, E., 1974: Teleological and Teleonomic: A New Analysis, "Boston Studies in Philosophy of Science" 14, pp. 91-117.

Mayr, E., 1988a: Cause and Effect in Biology (1961), in Id., Toward a New Philosophy of Biology, Harvard University Press, Cambridge, MA/London, pp. 24-37.

Mayr, E., 1988b: The Multiple Meanings of Teleological, in Id., Toward a New Philosophy of Biology, Harvard University Press, Cambridge, MA/London pp. 38-65.

Mayr, E., 1988c: The Concept of Finality in Darwin and After Darwin (1983), in Id., Toward a New Philosophy of Biology, Harvard University Press, Cambridge, MA/London pp. 233-257.

Mayr, E., 1992: The idea of Teleology, "Journal of the History of Ideas" 53 (1), pp. 117-135.

Pittendrigh, C. S., 1958: Adaptation, natural Selection, and Behavior, in Roe, G., Simpson, G. (eds.), Behavior and Evolution, Yale University Press, New Haven, pp. 390-416.

Quarantotto, D., 2005: Causa finale, sostanza, essenza in Aristotele. Saggio sulla struttura dei processi teleologici naturali e sulla funzione del telos, Bibliopolis, Napoli.

Vitale, F., 2017: With or Without You...Deconstructing Teleology between Philosophy and Biology, "The Oxford Literary Review" 39 (1), pp. 82-100.

Vitale, F., 2018: Biodeconstruction. Jacques Derrida and the Life Sciences, SUNY Press, Albany, NY.

Wiener, N., 1965: Cybernetics, or Control and Communication in the Animal and the Machine, MIT Press, Cambridge, MA. 